\title{
Parents' Voice: Parents' Emotional and Practical Coping with a Child with Special Needs
}

\author{
Tali Heiman \\ Department of Education and Psychology, The Open University of Israel, Ra'anana, Israel \\ Email: talihe@openu.ac.il
}

How to cite this paper: Heiman, T. (2021). Parents' Voice: Parents' Emotional and Practical Coping with a Child with Special Needs. Psychology, 12, 675-691. https://doi.org/10.4236/psych.2021.125042

Received: April 9, 2021

Accepted: May 15, 2021

Published: May 18, 2021

Copyright $\odot 2021$ by author(s) and Scientific Research Publishing Inc. This work is licensed under the Creative Commons Attribution International License (CC BY 4.0).

http://creativecommons.org/licenses/by/4.0/

\begin{abstract}
Raising a child with special needs is challenging for most parents. The current study sought to focus on the emotional feelings of parents of children diagnosed with autism spectrum disorder, with attention deficit/hyperactivity disorder, or with learning disabilities. This qualitative study examined 41 parental retrospective perceptions and feeling regarding six aspects: 1) Emotional feelings toward the child referring to different period of his/her life. 2) Emotional feelings in the marital relationships. 3) Personal feelings of the parent. 4) Emotional feelings toward the educational systems. 5) Support and coping. 6) Needs and thoughts regarding the future. Findings revealed that parents from all groups, were experiencing a difficult period following diagnosis and in their daily routines. They described a lot of stress, anxiety, and anger. Some parents described their relationships as unstable and as involving conflicts and disagreements, others adopted a more positive mindset and with the challenges they were facing. Many parents referred to the emotional support and guidance they were receiving either as part of a support group or by visiting a therapist. The present findings contribute to our knowledge regarding the emotional experience of parents raising a child with disability, and highlight the vulnerability of parents with a child with special needs.
\end{abstract}

\section{Keywords}

Parents, Emotional, Support, Coping, Disabilities

\section{Introduction}

Raising a child with special needs is a highly challenging and often overwhelming task for parents. As the actual parents' perceived condition, the child is unlikely to become able to lead an independent, routine adult life, parenting seems 
to be parents' life-long mission. Various studies have shown that parenting a child with special needs comes at a high emotional, financial and familial cost (Craig et al., 2020; Hayes \& Watson, 2013). The aims of the qualitative study are to examine parents emotional and behavioral coping with their child diagnosed either with Autism Spectrum Disorder (ASD), learning disabilities (LD) and with Attention Deficit/Hyperactivity Disorder (ADHD), and to add to our understanding whether there are specific differences or similar coping behaviors of the parents. Specifically, the study examined parental retrospective perceptions and feeling regarding six aspects: 1) Emotional feelings toward the child referring to different period of his/her life. 2) Emotional feelings in the marital relationships. 3) Personal feelings of the parent. 4) Emotional feelings toward the educational systems. 5) Support and coping. 6) Needs and thoughts regarding the future.

Parenting children with special needs typically forces the parents to deal with an avalanche of practical demands, such as adjustment of the home environment and schedule, fewer job opportunities, continuous time pressure, financier expenses on various specialists and therapists, etc. (Power et al., 1988). These demands are challenging and often impact every aspect of the family life and one's own life: interpersonal aspects (existing or occurring conflict or support from another person), the intrapersonal aspect (existing or occurring conflict or emotional stress within the self or within one's mind), and practical coping.

\subsection{Emotional Coping: Obstacles and Facilitators}

The prospect of lifelong parenting to children with special needs is accompanying with increases psychological difficulties and pressure experienced by the parents and is likely to shape their perception of parenting and of the entire family's future (Bekhet, 2018; Karst \& Van Hecke, 2012). Among the studies focusing on the emotional obstacle, or negative feelings, for parents with a child with disabilities, we can find variables as stress, feelings of distress, depression, anxiety and guilt. Studies have shown this stress is related not only to the child's characteristics and behavioral difficulties but also to the myriad of other familial, financial and practical adjustments required to meet the child's needs, all of which initially affect the parents' quality of life (Hayes \& Watson, 2013; Karst \& Van Hecke, 2012). It is therefore unsurprising that depression and anxiety rates among parents of ASD children are higher not only in comparison to parents of typically developing children, but also in comparison to parents of children with different developmental delays or disabilities (Almansour et al., 2013; Bekhet, 2018; Karst \& Van Hecke, 2012). A meta-analysis analyzing 44 studies found that parents of children with ADHD also show higher levels of stress than parents of typically developing children; the severity of child's ADHD symptoms was found to be related to the level of parental stress (Theule et al., 2013), and parenting a child with LD (Dyslexia) was also increase parenting stress and depressive symptoms (Carotenuto et al., 2017; Multhauf et al., 2016). 


\subsection{Parents' Emotions Coping: Negative and Positive Aspects}

Various studies included within the term "emotional coping" negative aspects as stress, angry, anxiety, guilt, etc., only few studies also referred to positive aspects of emotional coping, as cohesiveness, sharing responsibility. Results confirmed that parents of children with ADHD experience more parenting stress than parents of nonclinical controls and that severity of ADHD symptoms was associated with parenting stress (Theule et al., 2013). Similar results were found among parents of children with ASD who reported on high levels of parenting stress, including traumatic stressors and trauma-related symptomatology (Stewart et al., 2017).

Few studies reported on the positive emotional coping, mainly focused on families with ASD children. The positive emotional aspects referred to feeling of connectedness, resilience, satisfaction, and family cohesion. Several studies found that parents to children with ASD reported on positive feelings, such as enhanced sense of meaning, family connectedness, and empowerment (Bekhet, 2018), others reported on personal optimism, hopeful thinking, sense of coherence, emotional health and problem-focused coping styles (Ekas et al., 2016; Lai \& Oei, 2014). Another positive aspect, referred to marital satisfaction as an important predictor of parenting experiences, particularly for fathers, with children with ASD (Hartley et al., 2011). Studies on family functioning and coping mechanisms among parents of children with ASD (Altiere \& von Kluge, 2009) found an increasing level of cohesion as related to increased use of coping behaviors.

\subsection{Parents' Relationships}

The relationships of parents to children with special needs seem to have different approaches towards coping with their new situation, when their child is diagnosed with a disability. It can be constructive and encouraging or on the other side, destructive and negative.

In addition to the emotional burden of caring for a child with a disability, families face a multitude of practical demands. These demands include continuous time pressures, significant financial burden, the need for support and accommodations for their child's education, greater investment in healthcare and in accessing medical care, and constant self- and child-advocacy (Lord \& Bishop, 2010; Morrison et al., 2009).

Few studies have shown that for a small part of the parents, the difficulties in raising a child with special needs can breed new intimacy and affection. For example, it was found that among parents of a child with ASD, when the maturing child is ready and able to move out and live independently, the parents display more optimism regarding their relationships and the approaching possibilities to use their leisure time (Hock et al., 2012). Mothers of adolescents with ASD were found to devote more time to providing childcare and completing household work and less time participating in leisure activities than mothers of typically developing children (Smith et al., 2012), in addition, the limited time to work 
increases financial stressors on families and may also diminish parents' resources for both social and emotional support (Karst \& Van Hecke, 2012).

Familial, friends, or others providing social support for the parents in their daily struggle, appears to be one of the most crucial factors when raising a child with disabilities, as it acts to reduce the associated negative psychological and physiological effects (Ekas et al., 2016; Lovell et al., 2012). A study of parents to individuals with ASD found that informal social support partially mediated the connection between the parent's burden and his/her quality of life (Marsack \& Samuel, 2017). A recent review of studies exploring coping strategies of parents to children with ADHD also shows the parents, especially mothers, sought more social support than the mothers of typical developmental children (Craig et al., 2020). It is interesting to note that the most helpful kind of support seems to be informal support, offered by family and friends, while formal support offered by professionals in the community does not seem to have the same effect; this differentiation is further addressed below.

The responsibilities related to parenting a child with disabilities require much energy, time and emotional investment, often raising familial conflicts. Mothers of children with ASD report they feel their entire day is dedicated to caretaking. Such parents find it extremely difficult to engage in hobbies or leisure activities. Mothers of adolescents with ASD reported spending less time in leisure activities and more time in childcare and household chores than mothers of typical adolescents (Smith et al., 2012), and reported having fewer opportunities to relax and have fun (Nealy et al., 2012).

Parents of children with ASD report less marital satisfaction, display higher divorce rates and have more conflicts regarding childrearing than the parents of typical developmental children (Saini et al., 2015). During adolescence, parents of adolescent boys with comorbid ADHD reported poorer communication with their children, including greater parent-child conflict, anger intensity and aggressive reactions compared to parents of typical adolescents (Edwards et al., 2001).

Families with an adolescent with ADHD exhibit higher levels of conflict than other families, particularly when the adolescent exhibits oppositional behavior. These families report arguing about more issues, feeling more anger, and using more negative communication than families without an adolescent with ADHD (Edwards et al., 2001). When interacting with their children, parents of children with ADHD are less responsive, more over-reactive, more controlling (Johnston et al., 2006) and show low levels of parental support (Haydicky et al., 2015).

Previous researches examined the family system and parents' perceptions regarding children diagnosed with an intellectual, physical, or learning disability, revealed that most parents had to make changes in their social life and expressed high levels of frustration and dissatisfaction, and emphasized the importance of social resources and support (Heiman, 2002). Parents perceived their family's expressive feelings as lower, the family organization as stricter, with a lower 
support than the control groups of parent (Heiman \& Berger, 2008). It appears that mothers of children with ASD were concerned regarding their child's ability to adjust to an independent adult life, to find employment and proper living arrangements (Meirsschaut et al., 2010; Nealy et al., 2012).

Limited research exists regarding the parenting emotional experience of children with these specific disabilities as related to the parents' perspective from birth to adulthood, parental perceived personal well-being and their ability to cope. Therefor, this study will focus on various aspects regarding the child, marital relationships, the educational systems, support and coping, and thoughts regarding the future.

\section{Participants}

Participants included 41 parents (34 mothers, 7 fathers) were individually interview, face to face, in their house or at their child school. Mothers age ranged from 40 to 64 (Mean age $=48.17$ ), and fathers age ranged from 45 to 56 (Mean age $=51.43)$. The education level of the parents included high school $(15 \%)$, undergraduate or with a diploma (50\%), postgraduate (35\%). The socio-economic level of the parents was medium to high. All of them are married and live in an urban environment. The disabilities included 10 children diagnosed with ASD, 23 children with ADHD, and 8 children with LD as a primary diagnosis ( 29 boys and 12 girls). The children age ranged from 3 years thru 34 years old. Table 1 shows the data of the study's participants, parents age, and their child characteristics.

\section{Procedure}

After receiving the Ethical approval from the university ethical committee, with the help of undergraduate students from education and psychology department, convenience sampling was performed. The participants were 41 parents of children previously diagnosed with ASD, ADHD and LD. The diagnosis was made either by a clinical psychologist, or a neurologist. The researcher contact by phone parents, asking them to contribute to the research study. The parents were very cooperative, they wanted that their story will be heard for details. The interview was based on the 8 general questions, focusing on their feelings toward the child, the marital relationships, feelings regarding themselves, toward the educational systems, receiving support, daily coping, their future expectations and needs. Each interview ranged from 50 to 120 minutes.

\section{Data Analysis}

The qualitative data was analyzed based on the 41 parents' interviews. Parents responses were recorded and the transcripts. The main themes and the repeated expressions and words were noted by two evaluators who are familiar with qualitative analysis. Based on qualitative analyses process recommendation (Smith et al., 2012), the evaluators re-listen to the records and re-read the transcripts, 
Table 1. Participants and their child data.

\begin{tabular}{|c|c|c|c|c|c|}
\hline $\mathrm{N}$ & Participants & Age & Child age & Child gender & Child disability \\
\hline \multicolumn{6}{|c|}{ Mothers } \\
\hline 1) & & 64 & 28 & girl & ADHD \\
\hline 2) & & 58 & 28 & boy & ADHD \\
\hline 3) & & 48 & 18 & boy & ADHD \\
\hline 4) & & 48 & 15 & boy & ADHD \\
\hline 5) & & 50 & 20 & girl & ADHD \\
\hline 6) & & 48 & 16 & boy & ADHD \\
\hline 7) & & 48 & 17 & girl & ADHD \\
\hline 8) & & 40 & 13 & boy & ADHD \\
\hline 9) & & 58 & 34 & boy & ADHD \\
\hline 10) & & 43 & 15 & girl & ADHD \\
\hline 11) & & 50 & 21 & girl & ADHD \\
\hline 12) & & 50 & 19 & boy & ADHD \\
\hline 13) & & 50 & 14 & girl & ADHD \\
\hline 14) & & 50 & 6 & boy & ADHD \\
\hline 15) & & 50 & 3 & boy & ADHD \\
\hline 16) & & 45 & 20 & boy & ADHD \\
\hline 17) & & 45 & 17 & boy & ADHD \\
\hline 18) & & 45 & 7 & girl & ADHD \\
\hline 19) & & 45 & 20 & girl & $\mathrm{ADHD}$ \\
\hline 20) & & 45 & 18 & boy & $\mathrm{ADHD}$ \\
\hline 21) & & 45 & 12 & girl & ADHD \\
\hline 22) & & 50 & 18 & boy & ADHD \\
\hline 23) & & 48 & 10 & boy & Learning disability \\
\hline 24) & & 51 & 23 & boy & Learning disability \\
\hline 25) & & 51 & 19 & boy & Learning disability \\
\hline 26) & & 50 & 15 & girl & Learning disability \\
\hline 27) & & 43 & 10 & boy & Learning disability \\
\hline 28) & & 45 & 16 & girl & Learning disability \\
\hline 29) & & 42 & 11 & boy & Learning disability \\
\hline 30) & & 50 & 17 & boy & Autism Syndrome \\
\hline 31) & & 50 & 9 & boy & Autism Syndrome \\
\hline 32) & & 42 & 14 & boy & Autism Syndrome \\
\hline 33) & & 40 & 16 & boy & Autism Syndrome \\
\hline 34) & & 50 & 18 & boy & Autism Syndrome \\
\hline \multicolumn{6}{|c|}{ Fathers } \\
\hline 35) & & 56 & 20 & girl & ADHD \\
\hline 36) & & 50 & 11 & boy & Learning disability \\
\hline 37) & & 56 & 17 & boy & Autism Syndrome \\
\hline 38) & & 56 & 9 & boy & Autism Syndrome \\
\hline 39) & & 45 & 17 & boy & Autism Syndrome \\
\hline 40) & & 52 & 17 & boy & Autism Syndrome \\
\hline 41) & & 45 & 18 & boy & Autism Syndrome \\
\hline
\end{tabular}


identify the unique language of the parents, and the specific pattern or concept from participants' interviews. The evaluators discuss the cases until they found a theoretical saturation, and no new themes emerge from the texts.

\section{Results}

\subsection{Parents' Feelings towards the Child}

The first question referred to the parental feeling toward their child. Most parents insisted to describe the process the family experienced regarding different periods and events in the child's life. Therefore, five themes were consisted from the interviews: the diagnosis process, childhood, elementary school period, adolescence, and young adults' period.

\subsubsection{Diagnosis Process}

Most mothers described the process of diagnosis as a difficult emotional experience accompanied by fear, stress and as a personal failure.

“The diagnosis was terrible. He [the child] didn't do anything. They [the psychologist] wouldn't let me in and I was afraid that he would fail. He didn't cooperate nearly anything" (a mother to a 9-year-old child with ASD). The parents described the diagnostic process as they, the parents themselves, are tested. In addition, the parents felt helpless during the diagnosis process, full of fear for the child incorrect responses, his cooperation and ability/inability, stressed for the decision of the psychologist.

"The diagnostician gave him all sorts of tasks, and he [the child] just looked at me. I could not help him. I felt that I was getting nervous and stressed, I felt as I failed" (a mother to a 13-year-old boy with ADHD).

Another strong feeling that was expressed by mothers during the diagnosis process was as a feeling of guilt. Mothers referred to their pregnancy period, "During all the pregnancy I smoked. I couldn't quit smoking, and now it seemed to me as the punishment that I did not stopped smoking I felt guilty." (mother to a 14-year-old girl with LD).

On the other hand, some parents noted that they felt that something is wrong with their child, and now, after hearing the diagnosis final results, they felt relaxed or felt "pleased" as they noted that "it was only hyperactivity disorder". Parents convinced themselves that ADHD is very frequent nowadays. "I was afraid that the diagnosis would reveal that he had also a problem with his IQ. When I was told that his IQ was at the average, I calmed myself. I wasn't sad. Today almost in every child you can find a problem. Today is normal." (a mother to a 12-year-old boy with ADHD).

\subsubsection{Childhood Period}

The childhood period, was described by parents as a very difficult time, along parents had to change their daily routine life, they do not have time to deal with their grief about the non-expected ideal child, as they had to adjust to their child, and to accept to modify their plans, trying to realize that the disability is for ever. 
It appears that during this period of the child (approximately from 1 to 6 years), most parents felt shamed (of the child) and guilty (of themselves). "The first time I remember I felt bad and even ashamed of his behavior, was when we had his birthday. We invited the family and our friends. I remember making him a cake in the form of a train and we decorate his chair with balloons. He sat pretty scared and didn't know what was all about... he began screaming and crying" (a mother to a 3-year-old boy with ADHD). A similar situation was described by a father that emphasized his helplessness: "I wanted him to be happy like all the children of my friends who celebrated their birthday, but we couldn't. I almost cry" (a father to a 9-year-old boy with ASD).

\subsubsection{Elementary School Period}

Parents of children with children with special needs use coping strategies, emotional and cognitive, that help tackle the challenging situations of raising their child. Coping referred to constantly changing cognitive, emotional and behavioral efforts to manage specific external and/or internal demands that are challenging or exceeding the resources of the person (Lazarus \& Folkman, 1984). Most parents' responses described complex emotional feelings including shame, embarrassment, anger and sadness, combined with enormous effort to ameliorate their child social, behavioral and academic environment, and with a lot of expectation from the school period.

"What I can remember from that period of elementary school is a lot of shame, anger and a lot of sadness. It was not pleasant to hear all the time that the child was not listening in classes, that the child did not do his homework, that he failed in tests. Every time when the teacher called me to school, I was in terrible embarrassment. I couldn't show his final notes to anyone." (a mother to a 13-yearold child with ADHD).

Another mother to a child with ASD describes her pain concerning the child's social aspect. "What hurts me is that he had no friends at all. No one came to him after school, and no one invited him either. He arrives home from school and sits in front of the TV all the time. I called other mothers and asked them to speak to their children to invite him or to come to us. I was willing to do anything for him to have friends. I felt pity and painful."

\subsubsection{Adolescent Age}

At the end of the elementary school period, and the beginning of the middle school, parents become more tired and frustrated, and parenting work develops into a circular structure: stuck, skipping, re-loaded, stuck again and try another strategy. Despite all their efforts, they find out every time new problems arise. The child does not prepare his homework, he does not fill his duties at home, the passage from elementary school to the other school creates more social difficulties, and moreover, they try to change therapist, doctors, coping strategy, etc.

The frustration and fatigue of the child's management leads to periods of giving-up. Giving up in this framework is a mechanism of self-protection or per- 
sonal or marital survival that allows parents time reorganize emotionally, and practically with their child difficulties. Parents described this time, as they are re-loaded for further experience, or a different practice, in order to find some answers or solutions to problems that arise.

Parents of children with special needs, generally, do not have much to tell about their child's achievement. The frustration grows and the feeling of discomfort is getting stronger during the adolescent age. Both parents felt tired coping with the child's adjustment in educational and social frameworks, to deal with the child difficulties, and even less to deal with their own difficulties as parents. They expressed some anger on the child, maybe because they know that there are a lot of things to fight on, things that the child cannot do or doesn't want to do, or understanding that thing will not be better for the child. Anger reaction is accompanied by a feeling of helplessness and frustration.

"Puberty age is very difficult. Everything comes in waves. Now he [the child] has a lot of stress and anxiety" (a mother of 17 years old boy with ASD).

\subsubsection{Feelings for the Child as an Adult}

The heavy and ongoing responsibility of the parents in addition to many difficult decisions, creates a sense of burnout and fatigue, which stem from constant energy, without any matching feedback from the child.

"I shall not forbid myself if something will happen to him, both physical and emotional injurie. I kept worrying that he might be injured. He is impulsive, act without thinking and it is very disturbing" (a mother of 18 years old boy with ASD).

Naturally, the future holds great uncertainty and fear of the unknown, but for parents of children with special needs, the worry and anxiety are stronger.

"There are no words to describe how much I care about the future. Worried about everything! Taking care of housing, for employment, who will take care of it, how to manage the hostel, will he be abused, who will take care of him? I am very concern and I feel lack of control" (a father of 17 years old boy with ASD).

"I already know he's going to have a hard time. Even now it's not easy for him to be different, I have nothing more to do. I did all my best for him. I hope he will work and get marries. I am very afraid that at the end he will be left alone as he was most years." (a mother of 34 years old boy with ADHD).

Even when it appears that the young adult experience the academic studies, as many of their peers, the parents still feel unease, "My boy study at the Open University. But my greatest worry of the future is his ability to have income and to maintain himself." (a mother of 23 years old boy with LD).

Contrary to parents' future concerns, few parents focused on the present life. They organize their life "step by step" and do not make programs to the future.

"I do not know about the future. Ask my husband. He [my husband] is constantly concerned about what will become of him [the child]? How he will complete his studies? What he is going to do? etc. He [my husband] is very disturbed about it. But I am not concern about the future. I am happy now, he [the child] 
has some friends, and he will find something to work." (a mother of 20 years old boy with ADHD).

\subsection{Parents' Feelings toward Each Other}

Parents, as a couple, are experiencing a difficult period after the diagnosis and along their daily practice, especially in light of the different ways of coping. Sometimes one of the parents describes the other partner, as a caring person, as an ignoring husband, or complained on the inconsistency in the emotional stage of the marital couple.

The relationships between were frequently described as unstable, along with conflicts and disagreements, "it was like a roller coaster, there were lots of crashes. I was in favor of trying and doing everything to proceed for success, but my husband was in emotional repression. There were many disputes and frictions between us" (Mother with a 14 years old of a boy with ASD).

In a similar way, the daily situation at home was described as exhausting, and feelings of solitude, "It all fell on me. I accepted the results of the diagnosis, but not my husband. A large separation was created at home. My life froze. I felt less working and less living. There was an agreement between my husband and me: he works and bring money, and I was taking care of the child. I felt as my life were taken from me" (a mother with a 16 years boy with ADHD).

On the other hand, there are parents that both of them, together, decided to cope with the new situation and the challenges. As such, both parents described years their communication as cooperative, "We were always doing everything together. Sometimes we have disagreement, but we are not angry at each other". In terms of emotions feelings that make the parents easier to cope, a father of a child with ASD (aged 9) said that "there was a time that we were always in the bedroom together with the child. Being all together helped me very much. I knew that there was support from each other and a lot of love."

\subsection{Parents' Feelings toward Themselves}

Parents expressed a variety for personal emotions that accompanying their daily life, raising their child with special needs. Following the question regarding the parents' individual feeling, most of the responses were on the "sad or unhappy" feelings scale, words such as loneliness, shame, guilt, anger and pain, frustration, anxiety and stress, and feeling of loss. Other expressed feeling of personal failure as a parent, embarrassment, and disappointment. Yet, some parents added positive feelings, as self-encouraging, optimistic thoughts, and hope.

"I feel an ongoing sadness and missing my life" (mother to a 15-year-old child with ADHD); another mother describes hard feelings of self-anger, guilt and frustration in looking back at the period of her son's elementary school, "more than anything makes me sad that today, I am mad at myself that I thought he is lazy and that he does nothing." Similar feelings were reported by another mother to a 28-year-old child with ADHD. She describes that she felt anger toward herself and hard feeling of self-failure. "I just felt falling down, that I had failed. I 
was very stressed and lonely, so I went to a psychiatrist and gave me pills and a three-week to rest at home."

Some parents adopted a more positive thinking, as a solution to more successfully manage their life. "There has always been a feeling of how it could be different. I learned to accept the other." With the time, he felt more empathy and responsive to for his child needs (a father of 17 years old boy with ASD). A mother told that the feelings that helped her to overcome are optimism and joy. "I keep laughing and looking for the good part in everything" (a mother to a child with ADHD, aged of 18).

\subsection{Parents' Feelings towards the Educational System}

One of the greatest challenges parents have by raising a child, is to deal with the educational system. It is well known that children with LD, ADHD and ASD experience more academic failures, in the education and social system. Parents revealed feeling of confusion and despair as a result of their need to coordinate with various professionals (such as school principal, counselor, school, psychologist, different teachers, social worker). Sometimes even though the children are very wise and knowledgeable, they have difficulties to learn and accomplish tasks. The school teachers tend to tell them to make more efforts, as sometimes they are considered be a lazy child. It appears that some parents felt that the educational system is not attentive to their child needs, and parents reflect anger and frustrations and disappointments, while few others felt that the school staff cordially include their child, and they were cooperative and helpful.

A mother to a child with LD describes that in elementary school, she [the mother] was very anger towards the system. "In the regular school, I realized that they didn't understand anything and my girl had no chance of surviving there. In the second grade, we transferred her to another school. There she received love and understanding. If she hadn't been there, she wouldn't have finished 12 years of schooling." Similar story was described aby another mother to a 10-year-old child with ADHD, "there have been plenty of anger on the educational system, they did not see him. Finally, we transfer him to another school to a special education class". And identical feelings of anger were described by a mother to a 16-year-old child with ASD, "anger, anger, anger. I'm so angry at school. They are not enough helping him and teachers are not enough attentive to his needs nor understanding".

However, in few cases, parents felt that one school person or the entire school team were very supportive and help with the inclusion of their child, "the psychologist's emotional support and his understanding, make me feel good, someone listen to me, help me to reduce my anxiety and stress" (a mother to a 14-year-old child with ADHD).

\subsection{Social Support}

Asking about the support the parent received, focusing on the emotional aspects, two main themes emerged: support from the close family members, and support 
outside the family.

Most parents indicated that they expected to receive more social and/or emotional support from the close and the extended family, but in most cases did not receive emotional support from the extended family. "Until we haven't asked for support, we didn't get. We [the parents] look strong and well-functioning, all seems to be OK, but actually, we have been in an economic and emotional crisis" (parents of child with ASD); another mother noted that not only that she did not get emotional support from the extended family, she felt that she had to support them, to hold on, "We couldn't talk to the extended family about our emotional experience. We were looking for understanding and empathy, not beyond that".

Sometimes, parents reported, that the communication expressed by the extended family, negatively effects their core family, interfere or even contradicted the family rules of behavior. "I did not receive emotional or practical support from the extended family; they sometimes even interfere with my children's education and aske me to leave them alone. It will be better they will not intervene at all" (a mother to a 10 years boy with $L D$ ).

Many parents referred to the emotional support and guidance they need, either within a support group, or individually with the help of a therapist, or a psychologist.

This emotional support helps them, among other things, to control their frustration, sorrow, and feelings of haplessness, and strength their resilience.

Several parents describe that they tried various therapies as attending parent's groups, parental training, and couples counseling. The mother of a 17 years old child with ASD indicates that, "the psychologist was very helpful, as I felt lost, with a lot of fatigue. But today, after many years, I feel again exhausted. It is difficult to talk to a therapist about my emotional state."

Another mother told that "we did go to a psychologist, me and my husband. He helped us very much, and prevented from us a lot of disagreements, because we talked about things. Raising a girl like this involves a huge emotional price from us as her parents. Parent must be emotionally helped, otherwise it is very hard to cope".

The emotional help, as described by some mothers, was very indispensable and useful, in order to continue as a couple and as functioning parents, "there were years when I thought I was lost. After many psychological sessions, I've learned to love myself as I am. Now I am more calm." Contrary to the most mothers who were favorite to get emotional support, fathers were less willing nor enthusiastic to proceed with the therapy sessions, "during five meetings our therapist just wanted to talk about the relationship between parents. so I finally went out in the middle of the meeting."

\subsection{The Future Expectations and Parents' Further Needs}

Raising the question about the future, parents' expectations, needs, and feelings revealed that all the participants expressed and expected a lot of challenges with 
their mature child, including social, medical, and economic concerns regarding the child. Most of the parents focused on practical expected solution, such as further caregiving costs, the ability of the child to work, and the burden or role of the sibling. Discussing parents' future needs involved a mixture of positive and negative practical and emotional solutions. Some parents focused on both: "The day my boy will leave the house and will start his independent life, I will be happy" (a father of a 17-year-old boy with ASD). Other parents suggested trying to find a target in the couple's life: "I tried a lot of workshops for the soul, such as art, music, riding horses; it makes me feel good, creative, and full of energy" (a mother to a19-year-old boy with LD). A few parents mentioned needing a vacation, wanting to travel, and feeling free without any commitment. Most of the parents concluded the interview with the words, "I hope to see myself and our children happy and content in life."

\section{Discussion}

This study intended to examine whether despite the various differences appears between the specific disabilities, parents' feelings and daily copping shares similarities or diversities regarding the child, regarding themselves, toward educational systems, support, and practical coping. As was previous discussed (e.g. Deault, 2010; Multhauf et al., 2016; Vernhet et al., 2019) the present findings contribute to our knowledge regarding the emotional experience of parents raising a child with ASD, LD, or ADHD, and highlights the vulnerability of both parents. In the present study, it was found that although a large part of the parents has been through the process of grief about the loss of the healthy child, they continue to cope during adolescence and adulthood period of their child, especially learning to manage in new situations of their child, with their pain and feeling of loss. These reactions create an emotional burden on the parents.

In many cases, parents remain alone with their emotions without the ability to share them with others. Parents have difficulty expressing anger and sometimes feel bitterness, which is a side effect of stress, fatigue and lack of attention to their needs. The extended family structure is disappearing and the nuclear family remains by herself (only mothers and fathers) alone in coping with emotional and physical confusion.

The difficulties may affect parents' conjugal relationships, cause conflicts, causing a higher misconception in the relationship, leading to a greater lack of satisfaction in the relationship, thereby might lowering the marital relationship quality (Jahangir \& Batool, 2017). When one of the children has attention deficit disorder, parents experience more stress and have more conflicts with their children, compared to parents with children without ADHD. In addition, the parents' relationships are influenced by the child behavior (Weyers et al., 2019).

The marital relationship quality between the couple is usually measured by the level of satisfaction from the marriage, the extent of commitment to the relationship and strategies for resolving interpersonal conflicts in relationships (Ben-Ari 
\& Lavee, 2011). Parents of children with ADHD perceive their parenting as more threatening and challenging because of everyday stress and negative feelings toward their child's behavior (Finzi-Dottana et al., 2011).

The present findings were in line with previous studies (e.g. Mofokeng \& van der Wath, 2017) that these parents are at risk of depression, marital problems, and other forms of personal distress. They experience less satisfaction from their parenting, that often lower their ability to cope with the child, and cause a feeling of lower parental capacity and lower self-esteem compared to parents of typical children (Williams et al., 2014) and the burden of raising a child with disability might affects the mental health of the parents (Mofokeng \& van der Wath, 2017). I addition, as was earlier found (Kendall, 1998), the existence of the disorder causes family tension, might evoke misunderstanding between the members of the family, and creates negative feelings in the family members. Parents experience long periods of hopelessness and despair, a deeper concern for their child's future and in the same time cause feelings of guilt, exhaustion and fear.

The findings of the present study provide insights into the role of social-emotional support for parents with a child with disabilities. This study contribution is by providing additional evidence for the important role of support. As many parents were seeking for emotional support, they displayed active strategies for daily struggling, as asking for support from family, friends and counselors, in order to manage their consistent loads and to reduce stressors associated with the child's disability. It appears that the parents' social-emotional support enhanced their positive feelings such as optimism and hope for a better future. Further in-depth qualitative and quantitative studies are needed to examine these aspects.

\section{Limitation and Implication}

The present study might have several limitations. The present study can be viewed as a pilot study. The findings present the voice of 41 parents, representing a homogeneous socioeconomic status in Israeli, because the participants belong to the middle and upper class. Further research should be performed using a larger and random sample of parents, illuminating the multiple sources and consequences of stress is imperative for arriving at applicable recommendations both for parents, and to development specific plans and the implementation for facilitating parental emotional management. Despite these limitations, findings from this study have important implications for research and practice, which add to those of previous studies showing that parents of children with various disabilities appear to experience intensified feelings, mostly negative, as loneliness, despair, along the different developmental periods. Yet, parents expressed positive expectations, faith and confidence in the future.

The current findings suggest implementing interventions programs, focused on increasing the emotional and social needs of parents with a disability, as well as to enhance the awareness of the educational teams and parents of typically 
developing children regarding the child's disabilities and their parents' needs. The findings also express parents' needs for beneficial coping, in order to increase their well-being and hope, and to reduce their negative feelings of stress and anxiety. Additional studies are needed to undertake comprehensive, longitudinal, in-depth mixed methods, including questionnaires and interviews and including a variety of families with different backgrounds, which might deepen our understanding of parents' feelings. Future research should also empirically examine counseling practices and training sessions in order to evaluate their effects on reducing negative feelings and stress, as well as strengthen parents' coping techniques to manage stressors. Therefore, it is recommended to support the parents in various ways, as it was previously demonstrated (e.g., Ekas et al., 2016; Karst \& Van Hecke, 2012) that support from the family members was associated with increased levels of optimism, and both family and friend's support was correlated with positive maternal well-being.

\section{Conflicts of Interest}

The author declares no conflicts of interest regarding the publication of this paper.

\section{References}

Almansour, M. A., Alateeq, M. A., Alzaharani, M. K., Algeffari, M. A., \& Alhomaidan, H. T. (2013). Depression and Anxiety among Parents and Caregivers of Autistic Spectrum Disorder Children. Neuroscience, 18, 58-63.

Altiere, M. J., \& von Kluge, S. (2009). Family Functioning and Coping Behaviors in Parents of Children with Autism. Journal of Child and Family Studies, 18, 83-92. https://doi.org/10.1007/s10826-008-9209-y

Bekhet, A. K. (2018). Depression, Positive Thinking, Personal and Social Resourcefulness among Caregivers of Persons with Autism Spectrum Disorders. Archives of Psychiatric Nursing, 32, 823-827. https://doi.org/10.1016/j.apnu.2018.06.006

Ben-Ari, A., \& Lavee, Y. (2011). Ambivalence over Emotional Expressiveness in Intimate Relationships: A Shift from an Individual Characteristic to Dyadic Attribute. American Journal of Orthopsychiatry, 81, 277-284. https://doi.org/10.1111/j.1939-0025.2011.01096.x

Carotenuto, M. et al. (2017). Maternal Stress and Coping Strategies in Developmental Dyslexia: An Italian Multicenter Study. Frontiers in Psychiatry, 8, 295. https://doi.org/10.3389/fpsyt.2017.00295

Craig, F., Savino, R., Fanizza, I., Lucarelli, E., Russo, L., \& Trabacca, A. (2020). A Systematic Review of Coping Strategies in Parents of Children with Attention Deficit Hyperactivity Disorder (ADHD). Research in Developmental Disabilities, 98, Article ID: 103571. https://pubmed.ncbi.nlm.nih.gov/31931455/ https://doi.org/10.1016/j.ridd.2020.103571

Deault, L. C. (2010). A Systematic Review of Parenting in Relation to the Development of Comorbidities and Functional Impairments in Children with Attention-Deficit/Hyperactivity Disorder (ADHD). Child Psychiatry \& Human Development, 41, 168-192. https://doi.org/10.1007/s10578-009-0159-4

Edwards, G., Barkley, R. A., Laneri, M., Fletcher, K., \& Metevia, L. (2001). Parent-Adolescent Conflict in Teenagers with ADHD and ODD. Journal of Abnormal Child Psychology, 29, 557-572. https://doi.org/10.1023/A:1012285326937 
Ekas, N. V., Pruitt, M. M., \& Mckay, E. (2016). Hope, Social Relations and Depressive Symptoms in Mothers of Children with Autism Spectrum Disorder. Research in Autism Spectrum Disorders, 29, 8-18. https://doi.org/10.1016/j.rasd.2016.05.006

Finzi-Dottana, R., Segal Triwitzb, Y., \& Golubchikb, P. (2011). Predictors of Stress-Related Growth in Parents of Children with ADHD. Research in Developmental Disabilities, 32, 510-519. https://doi.org/10.1016/j.ridd.2010.12.032

Hartley, S. L., Barker, E. T., Saltzer, M., \& Greenberg, J. S. (2011). Marital Satisfaction and Parenting Experience of Mothers and Fathers of Adolescents and Adults with Autism. American Journal on Intellectual and Developmental Disabilities, 116, 81-95. https://doi.org/10.1352/1944-7558-116.1.81

Haydicky, J., Shecter, C., Wiener, J., \& Ducharme, J. M. (2015). Evaluation of MBCT for Adolescents with ADHD and Their Parents: Impact on Individual and Family Functioning. Journal of Child \& Family Studies, 24, 76-94.

https://doi.org/10.1007/s10826-013-9815-1

Hayes, S. A., \& Watson, S. L. (2013). The Impact of Parenting Stress: A Meta-Analysis of Studies Comparing the Experience of Parenting Stress in Parents of Children with and without Autism Spectrum Disorder. Journal of Autism \& Developmental Disorders, 43, 629-642. https://doi.org/10.1007/s10803-012-1604-y

Heiman, T. (2002). Parents of Children with Disabilities: Resilience, Coping and Future Expectations. Journal of Developmental and Physical Disabilities, 14, 159-171. https://doi.org/10.1023/A:1015219514621

Heiman, T., \& Berger, O. (2008). Parents of Children with Asperger Syndrome or with Learning Disabilities: Family Environment and Social Support. Research in Developmental Disabilities, 29, 289-300. https://doi.org/10.1016/j.ridd.2007.05.005

Hock, R. M., Timm, T. M., \& Ramisch, J. L. (2012). Parenting Children with Autism Spectrum Disorders: A Crucible for Couple's Relationships. Child \& Family Social Work, 17, 406-415. https://doi.org/10.1111/j.1365-2206.2011.00794.x

Jahangir, H., \& Batool, S. S. (2017). Protective and Risk Factors of Marital Quality among Parents of Children with ADHD. Journal of Behavioural Sciences, 27, 108-126.

Johnston, C., Chen, M., \& Ohan, J. (2006). Mothers' Attributions for Behavior in NonProblem Boys, Boys with Attention-Deficit/Hyperactivity Disorder, and Boys with Attention-Deficit/Hyperactivity Disorder and Oppositional Defiant Behavior. Journal Clinical Child Adolescent Psychology, 35, 60-71. https://doi.org/10.1207/s15374424jccp3501 6

Karst, J. S., \& Van Hecke, A. V. (2012). Parent and Family Impact of Autism Spectrum Disorders: A Review and Proposed Model for Intervention Evaluation. Clinical Child and Family Psychology Review, 15, 247-277. https://doi.org/10.1007/s10567-012-0119-6

Kendall, J. (1998). Outlasting Disruption. The Process of Reinvestment in Families with ADHD Children. Qualitative Health Research, 8, 893-856. https://doi.org/10.1177/104973239800800609

Lai, W. W., \& Oei, T. P. S. (2014). Coping in Parents and Caregivers of Children with Autism Spectrum Disorders (ASD): A Review. Review Journal of Autism and Developmental Disorders, 1, 207-224. https://doi.org/10.1007/s40489-014-0021-X

Lazarus, R. S., \& Folkman, S. (1984). Stress Appraisal and Coping. New York: Springer.

Lord, C., \& Bishop, S. L. (2010). Autism Spectrum Disorders: Diagnosis, Prevalence, and Services for Children and Families. Social Policy Report, 24, 1-27. https://doi.org/10.1002/j.2379-3988.2010.tb00063.x

Lovell, B., Moss, M., \& Wetherell, M. A. (2012). With a Little Help from My Friends: 
Psychological, Endocrine and Health Corollaries of Social Support in Parental Caregivers of Children with Autism or ADHD. Research in Developmental Disabilities, 33, 682-687. https://doi.org/10.1016/j.ridd.2011.11.014

Marsack, C. N., \& Samuel, P. S. (2017). Mediating Effects of Social Support on Quality of Life for Parents of Adults with Autism. Journal of Autism \& Developmental Disorders, 47, 2378-2389. https://doi.org/10.1007/s10803-017-3157-6

Meirsschaut, M., Roeyers, H., \& Warreyn, P. (2010). Parenting in Families with a Child with an Autism Spectrum Disorder and a Typically Developing Child: Mothers' Experiences and Cognitions. Research in Autism Spectrum Disorders, 4, 661-669.

https://doi.org/10.1016/j.rasd.2010.01.002

Mofokeng, M., \& van der Wath, A. E. (2017). Challenges Experienced by Parents Living with a Child with Attention Deficit Hyperactivity Disorder. Journal of Child and Adolescent Mental Health, 29, 137-145. https://doi.org/10.2989/17280583.2017.1364253

Morrison, J. Q., Sansosti, F. J., \& Hadley, W. M. (2009). Parent Perceptions of the Anticipated Needs and Expectations for Support for Their College-Bound Students with Asperger's Syndrome. Journal of Postsecondary Education and Disability, 22, 78-87.

Multhauf, B., Buschmann, A., \& Soellner, R. (2016). Effectiveness of a Group-Based Program for Parents of Children with Dyslexia. Reading \& Writing, 29, 1203-1223. https://doi.org/10.1007/s11145-016-9632-1

Nealy, C. E., O’Hare, L., Powers, J. D., \& Swick, D. C. (2012). The Impact of Autism Spectrum Disorders on the Family: A Qualitative Study of Mothers' Perspectives. Journal of Family Social Work, 15, 187-201. https://doi.org/10.1080/10522158.2012.675624

Power, P., Dell Orto, A., \& Gibbons, M. (1988). Family Intervention throughout Chronic Illness and Disability. New York: Springer.

Saini, M., Stoddart, K. P., Gibson, M. et al. (2015). Couple Relationship among Parents of Children and Adolescents with Autism Spectrum Disorder: Findings from a Scoping Review of the literature. Research in Autism Spectrum Disorders, 17, 142-157. https://doi.org/10.1016/j.rasd.2015.06.014

Smith, L. E., Greenberg, J. S., \& Seltzer, M. M. (2012). Social Support and Well-Being at Mid-Life among Mothers of Adolescents and Adults with Autism Spectrum Disorders. Journal of Autism \& Developmental Disorders, 42, 1818-1826. https://doi.org/10.1007/s10803-011-1420-9

Stewart, M., Knight, T., McGillivray, J., Forbes, D., \& Austin, D. W. (2017). Through a Trauma-Based Lens: A Qualitative Analysis of the Experience of Parenting a Child with an Autism Spectrum Disorder. Journal of Intellectual \& Developmental Disability, 42, 212-222. https://doi.org/10.3109/13668250.2016.1232379

Theule, J., Wiener, J., Tannock, R., \& Jenkins, J. M. (2013). Parenting Stress in Families of Children with ADHD: A Meta-Analysis. Journal of Emotional and Behavioral Disorders, 21, 3-17. https://doi.org/10.1177/1063426610387433

Vernhet, C., Dellapiazza, F., Blanc, N. et al. (2019). Coping Strategies of Parents of Children with Autism Spectrum Disorder: A Systematic Review. European Child \& Adolescent Psychiatry, 28, 747-758. https://doi.org/10.1007/s00787-018-1183-3

Weyers, L., Zemp, M., \& Alpers, G. W. (2019). Impaired Interparental Relationships in Families of Children with Attention-Deficit/Hyperactivity Disorder (ADHD). Zeitschrift für Psychologie (Journal of Psychology), 227, 31-41. https://doi.org/10.1027/2151-2604/a000354

Williams, N. J., Harries, M., \& Williams, A. M. (2014). Gaining Control: A New Perspective on the Parenting of Children with AD/HD. Qualitative Research in Psychology, 11, 277-297. https://doi.org/10.1080/14780887.2014.902524 